\title{
Strength Analysis of the Carbon-Fiber Reinforced Polymer Impeller Based on Fluid Solid Coupling Method
}

\author{
Jinbao Lin, ${ }^{1}$ Yanjuan Jin, ${ }^{1}$ Zhu Zhang, ${ }^{1,2}$ and Xiaochao Cui ${ }^{1}$ \\ ${ }^{1}$ School of Applied Science, Taiyuan University of Science and Technology, Taiyuan 030024, China \\ ${ }^{2}$ State Key Laboratory of Explosion Science and Technology, Beijing Institute of Technology, Beijing 100081, China \\ Correspondence should be addressed to Jinbao Lin; linjinbao@qq.com
}

Received 19 December 2013; Accepted 11 April 2014; Published 28 April 2014

Academic Editor: Shaoyong Lai

Copyright (c) 2014 Jinbao Lin et al. This is an open access article distributed under the Creative Commons Attribution License, which permits unrestricted use, distribution, and reproduction in any medium, provided the original work is properly cited.

\begin{abstract}
Carbon-fiber reinforced polymer material impeller is designed for the centrifugal pump to deliver corrosive, toxic, and abrasive media in the chemical and pharmaceutical industries. The pressure-velocity coupling fields in the pump are obtained from the CFD simulation. The stress distribution of the impeller couple caused by the flow water pressure and rotation centrifugal force of the blade is analyzed using one-way fluid-solid coupling method. Results show that the strength of the impeller can meet the requirement of the centrifugal pumps, and the largest stress occurred around the blades root on a pressure side of blade surface. Due to the existence of stress concentration at the blades root, the fatigue limit of the impeller would be reduced greatly. In the further structure optimal design, the blade root should be strengthened.
\end{abstract}

\section{Introduction}

In the development of pumps for the corrosive, toxic, and abrasive liquids, it is important to choose suitable highstrength, corrosion resistant materials for the parts in contact with the liquids. However, even the use of high-alloy steels and alloys does not always provide the necessary safe and smooth operation of the pumps under the conditions of the chemical and other industries. Furthermore, pump components of special steels are extremely laborious to fabricate [1]. Consequently, studies are being conducted on the design and utilization of new structural materials possessing chemical resistance and good mechanical properties. In the last decades, the plastic and plastic-lined pumps were developed to deliver such media due to their high chemical corrosion resistance [2], whereas the plastic is not suitable for the cases of higher stress.

The most promising material is the fiber reinforced polymer composite. For example, carbon-fiber reinforced polymers (CFRP) are distinguished from other structural plastics by their combination of low density, high modulus of elasticity, high fatigue strength, thermal stability, low friction coefficient, and high wear resistance [3]. In this paper, the CFRP impeller as a key component of centrifugal pump is analyzed using one-way fluid-solid coupling method with the purpose of estimating the strength of the impeller.

\section{Numerical Model and Methodology}

The short carbon-fiber reinforced epoxy resin (one kind of CFRP) material characteristic parameters at room temperature of the impeller are shown in Table 1. Due to the long and short blades, composite impeller can improve the flow rate and increase the limited blades' correction coefficient $[4,5]$. In this work, the long and short blades composite CFRP impeller is designed according to orthogonal method $[6,7]$ and numerical simulation. Figure 1 shows the structure of the impeller and its finite element analysis model. The impeller's diameter is $0.18 \mathrm{~m}$, and the short and long space twisted blades are equal in number and arrange alternately.

In order to improve the accuracy of analysis, oneway coupled fluid-structure simulation method [8] is used for the strength analysis of the impeller. The steady flow patterns inside a pump are calculated by a CFD software FLUENT with the impeller revolving speed $3600 \mathrm{r} / \mathrm{min}$ and 
TABLE 1: The CFRP material parameters of the impeller.

\begin{tabular}{lcccc}
\hline Density $\left(\mathrm{g} / \mathrm{cm}^{3}\right)$ & Elastic modulus $(\mathrm{GPa})$ & Poisson ratio & Tensile strength $(\mathrm{MPa})$ & Compress strength $(\mathrm{MPa})$ \\
\hline 1.7 & 132 & 0.321 & 1222 & 536 \\
\hline
\end{tabular}

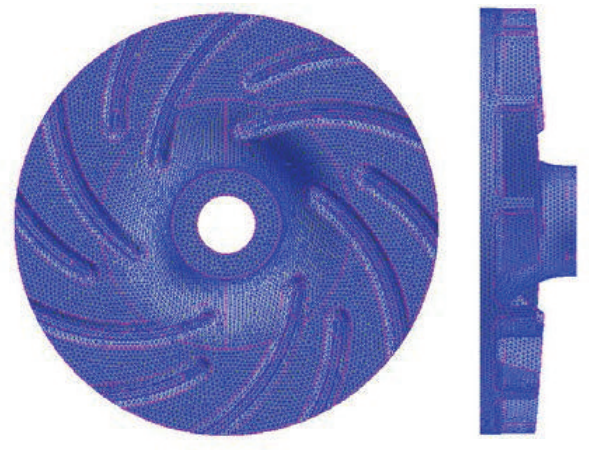

Figure 1: The structure and finite element analysis model of the impeller.

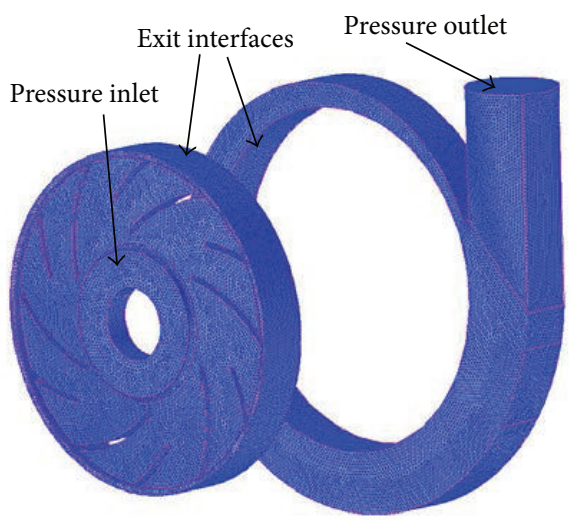

FIGURE 2: The fluid region with boundary conditions of impeller, volute, and outlet duct.

head $40 \mathrm{~m}$. Numerical simulation applies three-dimensional steady incompressible Reynolds averaged equations N-S and the standard turbulence model $\kappa-\varepsilon$ and uses SIMPLEC algorithm to achieve the coupling of pressure and velocity. Figure 2 presents the fluid region with boundary conditions of the impeller, volute, and outlet duct. The steady numerical simulation of structure dynamics is performed to predict the averaged stress using the finite element analysis software ANSYS.

\section{Calculation Results and Analyses}

The pressure and velocity fields in a coupling are obtained from the CFD simulation. Figure 3 shows the contours of the static pressure distributed in the pump. As expected for a centrifugal pump, the static pressure increases continuously from the inner to the outer region of the impeller due to the impulse of the blades. The high pressure regions are seen close to the outside edge of the blades. Additionally, flow

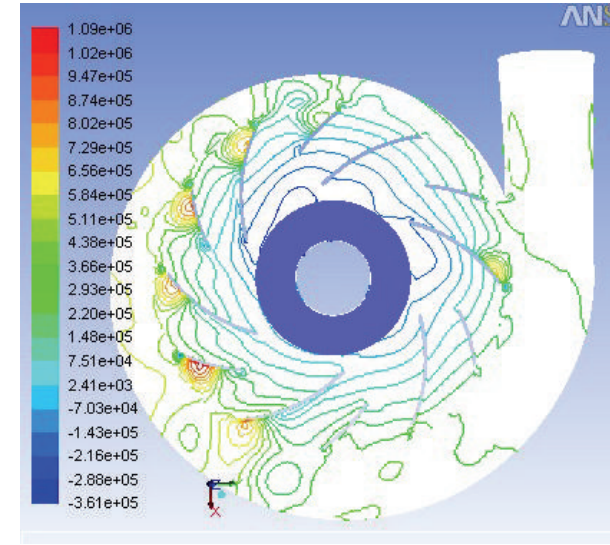

FIgURE 3: The distribution of the static pressure in the pump.

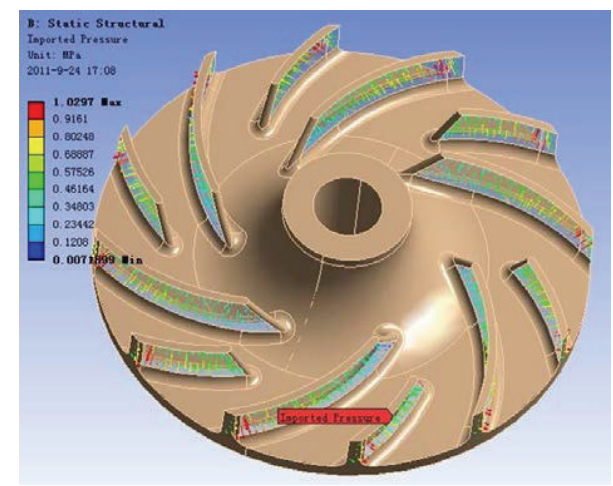

FIgURE 4: Static pressure distribution on the blades of impeller.

circulation from the pressure to the suction side of the blades can be observed in the figure. This circulation induces a small low pressure region near the trailing edge of the blades (pressure side).

The pressure distributions on the blade surfaces are transferred to the surface of the solid blade mesh, as shown in Figure 4; those are treated as the load conditions acting of the blades. Similar to the pressure distribution in the pump, the pressure on the blades increases continuously from the inner to the outer region, and there is a complicated pressure distribution on the surface of the blade due to the complex of flow.

Figure 5 shows the equivalent stress distribution of the impeller couple caused by the flow water pressure and rotation centrifugal force of the blade. It can be seen that there are certain stress concentrations at the root of some blades. The maximum stress is $23.6 \mathrm{MPa}$ at the root, which is the most adverse situation. As presented in Table 1, the minimum strength of CFRP is $536 \mathrm{Mpa}$; it is clearly indicated that the CFRP impeller can meet the requirement of 


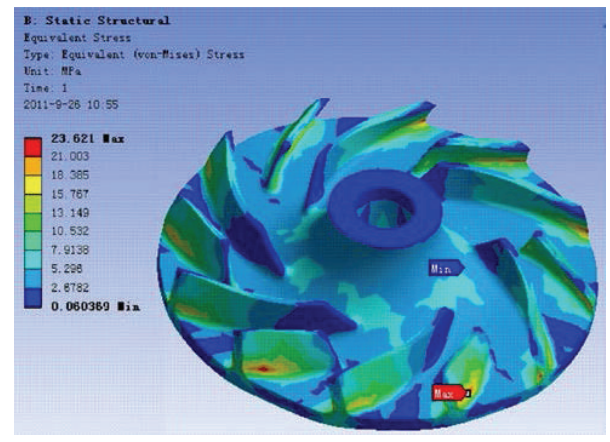

FIGURE 5: Equivalent stress distribution of the impeller.

the centrifugal pump. Nevertheless, due to the existence of stress concentration at the root, the fatigue limit of the blade would be reduced greatly which leads to the destruction under the action of the alternating stress caused by the rotation of the blade. So, in the further mechanical optimal design, the blade root should be strengthened.

\section{Conclusions}

The strength of the CFRP impeller is analyzed using one-way fluid-solid coupling method. The result indicates that (1) the pressure increases continuously from the inner to the outer region of the impeller due to the impulse of the blades. The high pressure regions are seen close to the outside edge of the blades. (2) The largest stress 23.6 MPa occurred around a blade root on a pressure side of blade surface; it indicates that the strength of CFRP impeller can meet the requirement of the centrifugal pump. (3) There is stress concentration at the root of the blade, which would be reducing the fatigue limit greatly. In the further structure optimal design, the blade root should be strengthened.

\section{Conflict of Interests}

The authors declare that there is no conflict of interests regarding the publication of this paper.

\section{Acknowledgments}

This work is financially supported by the National Natural Science Foundation of China (no. 51204117), the Natural Science Foundation of Shanxi (no. 2012021018-2), the Shanxi Scholarship Council of China (no. 2011-079), and the Program for the Top Young Academic Leaders of Higher Learning Institutions of Shanxi.

\section{References}

[1] V. V. Berezovskii, B. I. Molchanov, T. N. Polyakova, and P. A. Chukalovskii, "Prospects for using carbon-fiber reinforced plastics in pump construction," Chemical and Petroleum Engineering, vol. 17, no. 3, pp. 133-136, 1981.

[2] F. Bahm, "Plastic-lined centrifugal pumps for ultra-pure media," World Pumps, no. 454, pp. 36-38, 2004.
[3] H. Katogi, K. Takemura, and Y. Shimamura, "Mechanical properties of carbon fiber reinforced plastics under hot-wet environment," Key Engineering Materials, vol. 462-463, pp. 207212, 2011.

[4] K. Majidi, "Numerical study of unsteady flow in a centrifugal pump," Journal of Turbomachinery, vol. 127, no. 2, pp. 363-371, 2005.

[5] Y. Tian, X. Qi, and J. Hu, "Preferentialness design of a composite impeller with ultra-low unit speed centrifugal pump," Advanced Materials Research, vol. 308-310, pp. 2353-2357, 2011.

[6] S. S. Chen, Z. F. Zhou, Q. Ge, D. F. Yan, and L. S. Wang, "Orthogonal experimental study on centrifugal pump with deviated splitter vanes," Journal of Yangzhou University, vol. 8, pp. 45-48, 2005.

[7] S. Q. Yuan, J. F. Zhang, J. P. Yuan, and Y. D. Fu, "Orthogonal experimental study effect of maingeometry factors of splitter blades on pump performance," Drainage and Irrigation Machinery, vol. 26, pp. 1-5, 2008.

[8] K. Katsutoshi, O. Shigeyoshi, H. Ichiro, and C. Yoshimasa, "Numerical analysis of stress on pump blade by one-way coupled fluid-structure simulation," Journal of Fluid Science and Technology, vol. 5, pp. 219-234, 2010. 


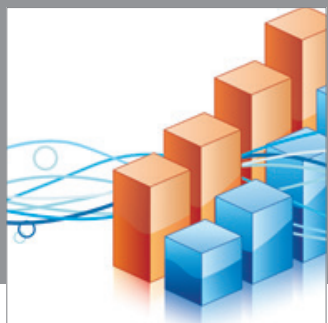

Advances in

Operations Research

mansans

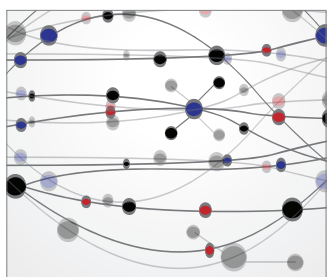

The Scientific World Journal
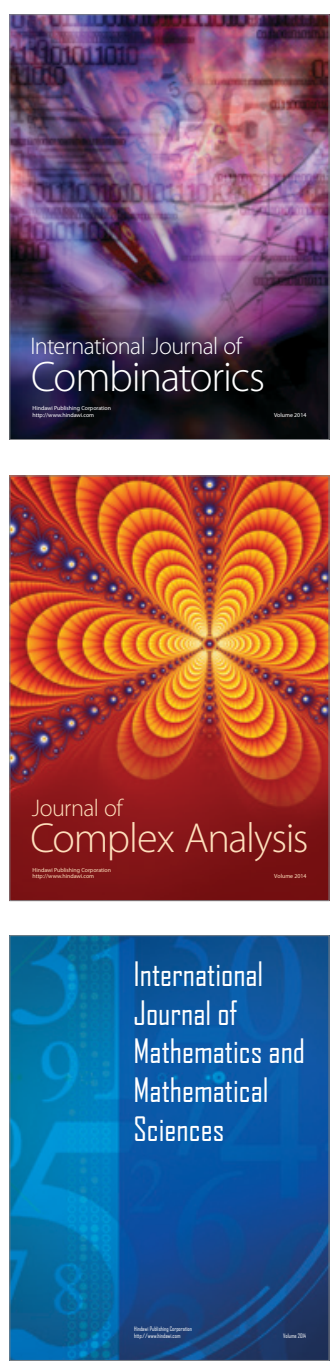
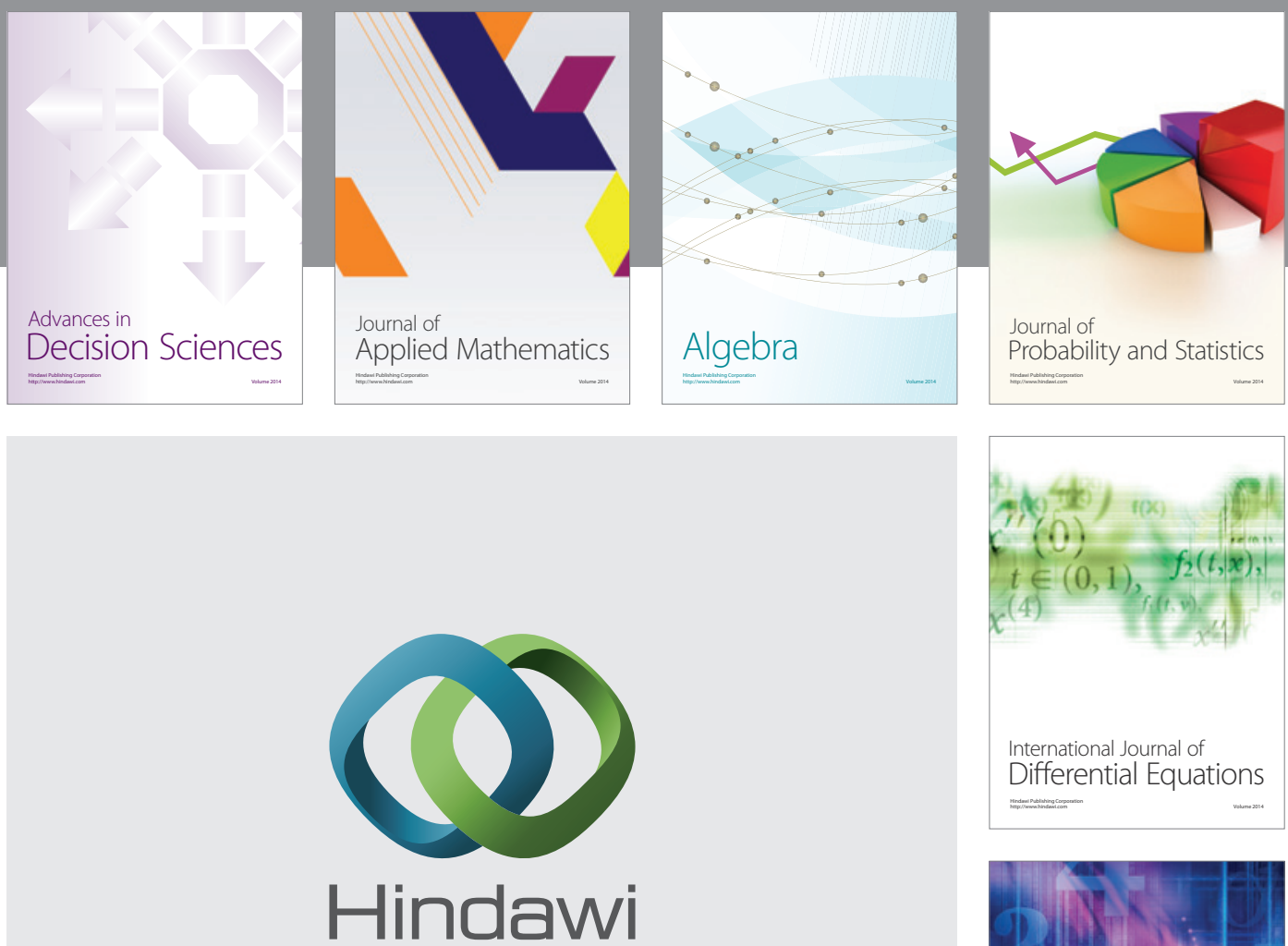

Submit your manuscripts at http://www.hindawi.com
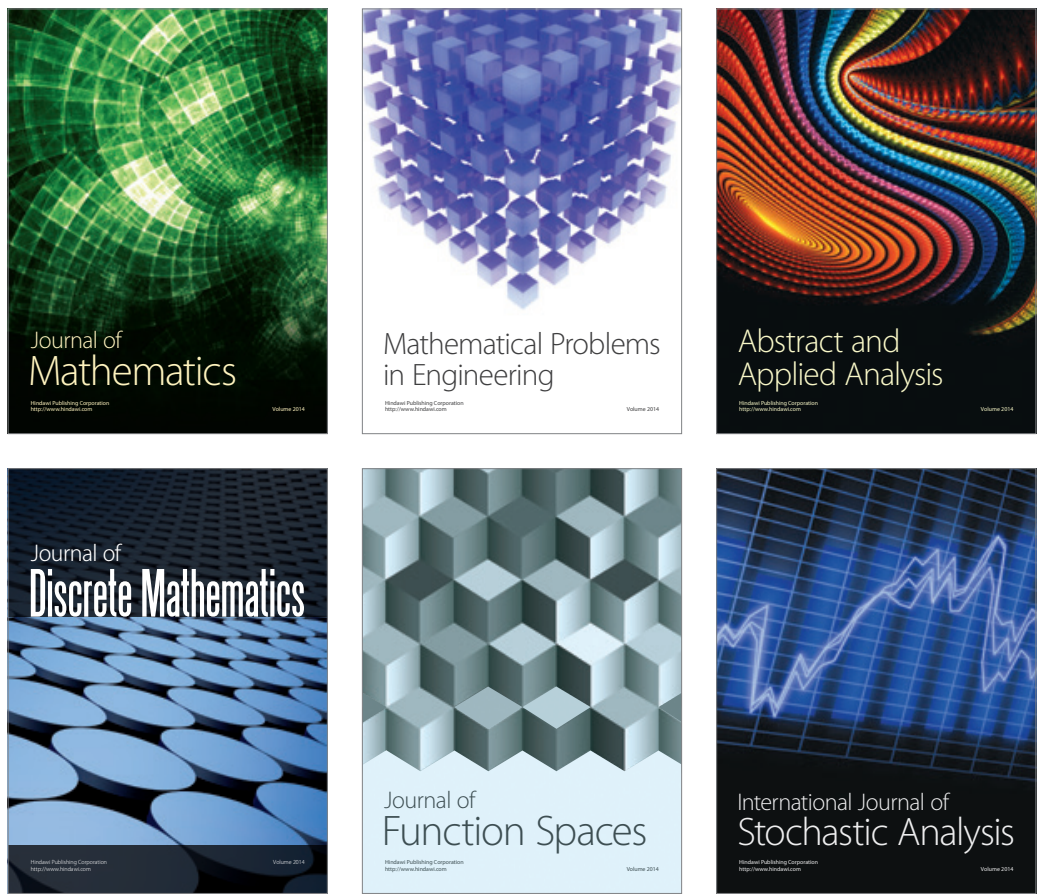

Journal of

Function Spaces

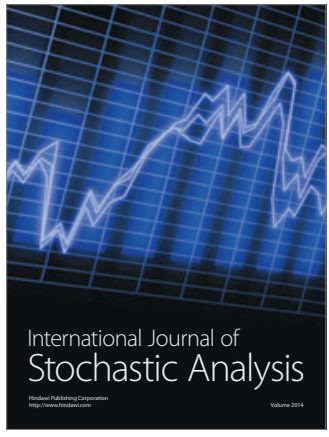

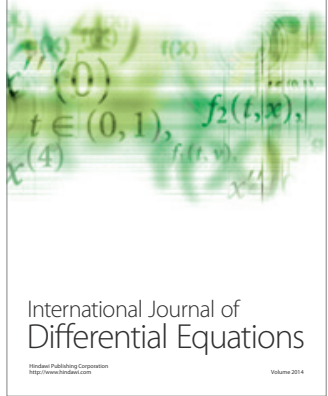
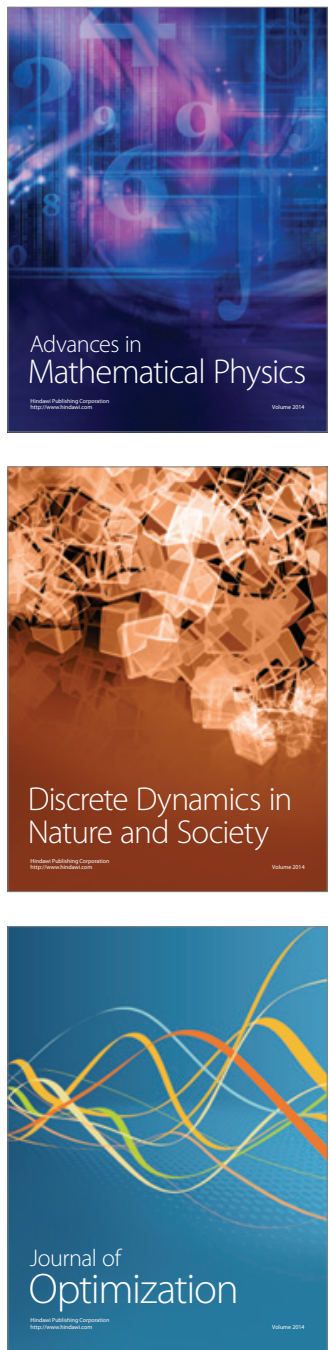